\title{
Stem Cell Technologies in Human Health: Boon or Bane?
}

\author{
Madhavi Tripathi, Sangeeta Singh* \\ Department of Applied Science, Indian Institute of Information Technology (IIIT), Allahabad, India \\ Email: "sangeeta@iiita.ac.in
}

Received 23 August 2015; accepted 2 November 2015; published 5 November 2015

Copyright (c) 2015 by authors and Scientific Research Publishing Inc.

This work is licensed under the Creative Commons Attribution International License (CC BY). http://creativecommons.org/licenses/by/4.0/

(c) $\underset{\mathrm{EY}}{\mathrm{B}}$ Open Access

\begin{abstract}
The stem cells of an organism only possess extraordinary capacity to change into different cell types during the early life and growth of an organism. When these stem cells divide into different new cells, these either remain as stem cells or develop to become other cells with specialized function. For this reason, stem cells offer direct relevance to human health, as theoretically, using stem cell technology, different organs are expected to be regenerated. To this, the Human Embryonic Stem Cells (HESCs) are natural pluripotent cell, but ethical issues covering many countries have put research work on a bit back-foot. However, the Induced Pluripotent Stem Cells (iPSCs) technology has completely revitalized the world to use this technology universally and it therefore seems that more research on this technology will surely be of enormous help in public health. In addition, application of the stem cell technology in personalized-medicine has been started recently. In this concern, the stem cell banking facilities have provided new avenues for preserving the cord blood of the new-borne child and treat them in future by using her/his own preserved stem cells. However, like all new technologies, the output from stem cell research requires to be evaluated more closely. Furthermore, with proper guidelines on ethical issues and extended research following these strategies, the stem cell technology is expected to not only be of huge benefit to human health, but also the benefit can be extended to the survival of endangered animals as well.
\end{abstract}

\section{Keywords}

Human Embryonic Stem Cells (HESCs), Induced Pluripotent Stem Cells (iPSCs), Human Health, Personalized Medicine

\section{Introduction}

Regeneration in an organism is considered to be both functional and morphological in nature, as the broken and *Corresponding author. 
destroyed parts are reconstructed once again [1]. However, in most organisms, capacity of regeneration is limited to some of the tissues only. One of the best explanations in this regard can be given by appearance of blastema at the site of injury which is said to be a mass of primitive totipotent cells [2]. After attaining some desired critical size, this cellular mass begins to grow and re-differentiates to produce the desired mass of tissue, giving rise to the formation of complete restored shape and with proper functioning tissue [3]. Unfortunately, we primates cannot perform this trick of regeneration of each and every body part, as capacity of regeneration is very limited in humans, except healing of fractures of long bones, renewal of red blood cells etc., which are good examples of regeneration in our body [4]. To this concern, stem cells are the ones found in our body showing potential of forming any kind of cells. These are considered to be of specialized cells because they bear interesting capacity to develop into many different kinds of cells both at the starting of life and during the growth period during the process of cell division, even these cells have remained inactive for a longer duration in the body. During the developmental processes of an organism, every newly generated cell form bear potential either to remain as a stem cell or develop into another cell type of very specialized functions [5]. For example, in gut and bone marrow, stem cells often divide to restore old and damaged tissues in a very proper manner, whereas in pancreas and heart, stem cells divide only under special conditions when required [6]. Based on the availability of different stem cells in different developmental processes and organs and on their ability to divide and differentiate, three kinds of cells are found in the life history of an organism: i) totipotent cells found in zygote, ii) pluripotent cells found in blastocyst and iii) unipotent or multi potent cells found in bone marrow [7]. Totipotent as the name suggests, have ability to form every kind of cell including extra embryonic cells, and pluripotent cells can form every kind of cell in our body except extra embryonic membranes and placenta. The totipotent cells are defined by their ability to produce both somatic and germ cells as well as extraembryonic tissues in mammals [8]. The maintenance of totipotent cells lies at the basis of the continuity of life from one generation to the next. Although the molecular mechanism involved in ensuring the totipotency in cells is not fully understood, several key molecules have been identified. Pluripotency is a state of cells when it can potentially develop into many kinds of cells found in our body but lacks potential which could make it totipotent. Certain cells in human body, e.g., Human Embryonic Stem Cells (HESCs) that are natural pluripotent cells found in the inner mass of early embryo bearing capacities to differentiate into any other type of cells except for placenta [9]. The Human Embryonic Stem Cells (HESCs) are the ones having normal karyotypic number and contribute to all living adult tissues and germline [10]. HESCs have capabilities of producing full embryonic stem cells (ESCs) derived animals when these are injected into blastocyst which is tetraploid [11]. Tetraploid blastocyst can only form extra-embryonic tissue, which comes in function when ESCs are injected into it to together form an adult individual [12]. Stem cells derived from epiblast cells have been isolated from post implantation embryos. Only ESCs have the perfect ability to pass developmental assay as they have perfect and balanced parental imprints required for normal developments in a developing organism. As seen till today, all the pluripotent cells tested have the capability to induce the required pluripotency in normal somatic cells after their cellular fusion with somatic cells [13], hence proving that they have noticeable programming activities as compared to normal cells [14]. Studies have been carried out to identify a group of transcription factors, which affects the pluripotent characters of the ES cells [15]. Few transcription factors, i.e. Nanog, Sox2 and Oct4 are important for maintaining ES cell identity [16].

\section{The Induced Pluripotent Stem Cells (iPSCs)}

As discussed above, the ability of pluripotency is defined by the presence of certain transcription factors in the cells and therefore, the adult somatic cells can be programmed to form some special kinds of cells known as Induce Pluripotent Stem Cells (iPSCs) [17]. Ever since it was understood that working with HESc involves several ethical concerns and pluripotent ability can become answer of many problems of medical science, research and application of iPSCs were initiated [18]. The iPSCs are therefore defined as the somatic cells, which have been transformed and reprogrammed to a pluripotent state. The iPSC technology had started from determining the regulatory mechanisms responsible for pluripotency and moved up to considering the differentiation potential of the cells in vitro and their therapeutic use in vivo [19].

In the last few decades enormous amount of research works have contributed to the advancement of research in iPSCs. Experimentally, it has been shown that cells gradually loose potential of being pluripotent and ultimately become differentiated [20]. Research works conducted in re-programming of nuclear transfer, transcrip- 
tion factors and HESCs have shed light on the development of iPSCs. In fact, the success story on the first animal (mammal) produced by somatic cloning of epithelial cells dates back in 1997, when Ian Wilmut and colleagues described the birth of Dolly sheep [21]. Thereafter, concepts of transcription factors that determine and induce the fate of a given ancestry were developed. Knowledge on the evidence of conditions that are required to culture pluripotent cells have enabled us to recognize some factors that can produce iPSCs [21]. This was possible due to the property of terminally differentiated cells to become pluripotent when stimulated [22]. While it was found that nearly all cells can be reprogrammed to form IPSCs, generation of iPSCs, which is a reproducible process but not very efficient, proceeds through integration and non-integration methods. For example, nearly $1 \%$ of overall fibroblast transfection results in formation of iPSCs. Due to the fact that i) the retroviruses used to generate iPSCs were not safe due to their insertional mutagenesis and ii) the techniques were majorly tested on mouse, it was not a surety for their use on humans. However, the finding on the immunogenic nature of lentivirus or retrovirus used to generate the iPSCs led to development of a new technique using plasmid vector to form mouse iPSCs [23]. A target was set in order to achieve transfection efficiency by using there reprogramming factors. These factors were combined in such a way so as to provide effective arrangement [24]. The Oct3/4, Sox2 and Klf4 are the three factors which were connected in a proper sequence in a plasmid [25]. The iPSC colonies are usually made of two kinds of cells: i) integrated cells, and ii) non-integrated cells. The integration-free cells have the ability and potential to form three germ layers and its cell types. This process however, was not very efficient as the frequency of iPSCs was very low. Currently, iPSC are generated without any kind of introduction of foreign gene. To this concern, temperature sensitive character of the Sendai virus proved very useful in formation of iPSCs from human fibroblasts and cord blood cells [26]. Also, a method was applied to generate iPSCs from frozen peripheral blood using a polycistronic vector which encoded for four transcriptional factors Klf4, Sox2, c-Myc and Oct4 [27]. This was one of the novel methods which can provide an easy access to the patient's blood [Figure 1].

What makes special about the iPSC? Experiments carried out over a period of time have informed us a lot about the molecular base of cell identity. The very characteristic feature of the pluripotent embryonic stem cells

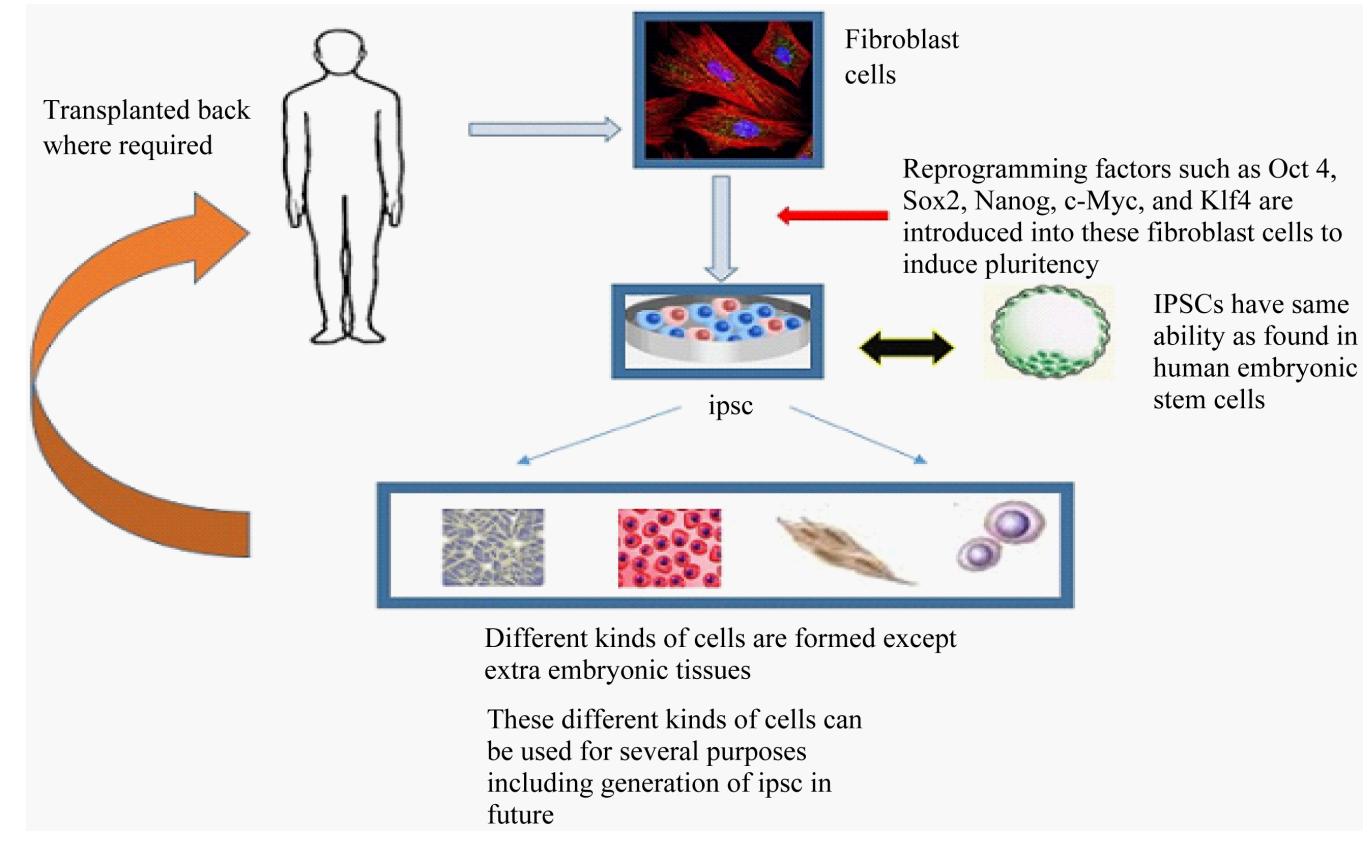

Figure 1. A flow chart showing how the Induced Pluripotent Stem Cells (iPSCs) can be formed from normal fibroblast cells using different reprogramming factors viz. Nanog, Klf4, Sox2, c-Myc and Oct4. To be noted that the iPSCs bear similar abilities as human embryonic stem cells i.e. capable to differentiate in any type of cell present inside the individual except placental cells and have potential to treat several human diseases like acute and chronic leukemias, myeloproliferative and lymphoproliferative disorders, inherited diseases, malignancies, etc. by modelling them. Several other kinds of cells can be formed during the process that can further be used for transplantation inside human body wherever required. 
is directed by number of transcription factors. Few among these transcriptional factors are important ones; such as Oct4, Sox2, c-Myc, Klf4, Lin28 and Nanog [28]. Presence of these factors in several combinations make cells capable of unspecified self-renewing and growth. To be noted that, 13Oct4, Sox2 and Nanog are the key regulators crucial for the establishment and up keeping of ICM in mouse pre-implantation embryos. Technologies directed towards research on stem cells are developing slowly but steadily for development of patient-specific pluripotent cell lines minus the somatic cell nuclear transfer (SCNT). Although the IPSC technology is advantageous due to its simplicity and its prospects of wide application, there is a strong need to generate patient specific stem cells [29]. In this concern, recent developments of patient-specific iPSCs have generated new hopes offering exciting possibilities in stem cell research [30]. Taken together, the HESCs and iPSCs offer excellent technological advancement for therapeutic purposes, and make them promising future tools for developmental biology and in field of regenerative medicine [31].

\section{Stem Cell Technology and Personalized Medicine}

With increasing accumulation of population genomic data of humans, especially on the genes responsible for metabolization of different drugs, it has been globally acknowledged the importance of development of individualized/personalized medicine [32]. Although at its infancy, the concept of personalized medicine is loud and clear; that each individual is very different in its capacity to metabolize different drugs. Using these populationbased information on the distribution of slow/fast metabolizing phenotypes, one can design drugs of different potency to suit each individual, by which each individual can metabolize the drugs very effectively [33]. To this effect, the iPSC technology has paved path which could contribute to ever increasing concept of personalized medicine. For example, research work using iPSC technologies on patients with retinitis pigmentosa (one of the leading cause behind loss of vision) has paved new ways in this concern. Specifically, using patient-specific cell lines suitability of gene therapy to correct genetic deficiency in patients has provided a new direction in the advancing technology of personalized medicines [34]. Transformation of skin cells into retinal cells which could be further used for preclinical testing and also to study patient specific model to study a disease has already been undertaken [35]. This step towards union of personalized medicines and iPSC is expected, which can answer for nearly all human health related problems in near future. In developing countries which serve as hub for generation of new mutant microbes for new infections and mutations related to many hereditary diseases, such studies could possibly bring a new era of public health.

\section{Issues and Limitations of Using Stem Cell Technologies in Human Health}

Although the Stem Cell Technology is very nascent and prove to be of extensive use public health, like all new technologies that requires time and validation, there are still several issues that have put this technology at the back foot for the moment. A major issue arises during induction of pluripotency using re-programming factors as the gene set itself is problematic. Ectopic transcription of Sox2, Klf4, c-Myc and Oct4 sometimes lead to abnormal neoplastic kind of development from iPSC derived cells, because expressions of these genes are found to be associated in formation of multiple tumors [36]. In case of breast cancers, an elevated expression of Klf4 and over expression of Oct4 causes dysplasia in murine epithelial cells [37]. In most of human cancer cases, expression of c-Myc is seen to be elevated [38]. It is very important to find substitute of Klf4 and c-Myc as it is quite possible that their ectopic expression can lead to formation of malignant tumors [39]. However, research work has proved that these can be easily substituted by Nanog and Lin. It is therefore quite pertinent to substitute such carcinogenic factors with more effective and safe factors. There is also a need to minimize the number of genes required for programming. In this concern, it is better if non-genetic factors could be used for this purpose. Another, disquiet has been raised on the induction of mutations in the iPSCs. The genome is much vulnerable to any kind of injury during the reprogramming and it can very easily lead to various types of mutations in iPSCs [39]. Also, productions of patient-specific iPS cells are outrageously expensive for majority of population. The feasibility of using the iPSC technologies in clinical advantages is not at all cheap. As compared to iPSC, the HESC-based products are much cheaper. However, iPSC has that potential which can offer a rich cell source for tissue engineering, as well as producing patient-matched models in vitro. For these limitations, research on genetic and environmental aspects in cartilage repair and osteoarthritis [40], and large bone defects are still proving to be challenges for the orthopaedic and reconstructive surgeon [41]. 


\section{Stem Cell Banking: A New Hope for Medical Treatment}

As discussed above, the stem cells are young cells that can reproduce themselves and have the potential to develop into other types of cells. Among several types of stem cells; the umbilical cord blood and bone marrow are termed as hematopoietic progenitor cells (HPCs) [42]. The cord blood of a new-borne child therefore contains powerful stem cells, which is collected immediately after birth and are preserved for future medical use. This process involves reserving the newborn child's umbilical cord and placenta immediately after birth. The process involves collection of the blood in a collection bag and appropriately preserved. Since these cells are biologically newer and much flexible in comparison to adult stem cells, medical fraternity uses these stem cells due to several exceptional abilities and benefits including i) Fewer risk of complications when used in transplants, ii) Capacity to use one's own stem cells for circumstances that lack treatment options, also known as "autologous transplantation", iii) Instantly available and can curtail disease progression in early treatment, and iv) Preserving them "stops the clock" and defends the cells from aging and being exposed to environmental influences and common viruses that can lessen their function [43]. Since the stem cells are the foundation of the blood and immune system, and possess the ability to grow into other types of cells, these can be used to repair tissues, organs, and blood vessels and to treat a multitude of diseases [44]. In case of a treatment failure or recurring of the same disease, doctors often go for stem cell transplant, which included transfusion of stem cells from the bone marrow, peripheral blood, or cord blood from a healthy donor, which can help in generating a new blood and immune system, by which a patient's chance of rescue increases manifold. So far, stem cells from the cord blood have been used to treat more than 70 diverse diseases that include some cancers, blood disorders, immune deficiencies, leukemia, aplastic anemia, thalassemia, Hodgkin's disease, and non-Hodgkin's lymphoma and other diseases [45]. The fundamental of a patient's own stem cells will help her/his body to repair itself is used here, as no concern that her/his body will discard his own stem cells or counter against them. However, there are instances when the body is manufacture the wrong cells-for instance, if the sickness is cancer or a genetic blood disorder, then the transplant must derive from a donor, not the patient's own cells [46]. This is simply because the patient's stem cells possibly carry the same deficiency that caused the cancer or the genetic disease, and one is transplanting the spores of the disease back into the patient. At present, more than 1 million units of cord blood are deposited in family banks in the United States, and several other countries around the world has adopted the cord blood banking methods for use in human health.

\section{Future Challenges and Opportunities}

In spite of the fact that the iPSC technology is a good answer for improvement of human health, not all countries of the world have embraced this technology with full faith yet. This is because, i) several issues concerning human ethics still exist, and ii) the technology has not taken into a well-established and full-proof platform. It is therefore, iPSC technology has not taken any big leap from where it has started initially. Majorly, the technological glitches involved in stem cell research have put major huddle into how safe is the iPSC technologies are. For example, partial reprogramming and abnormal gene expression in few cells differentiated from iPSCs can occasionally induce immune response in syngeneic recipients [47]. T-cell mediated immune response is occasionally seen and faces immune rejection which is yet another potential drawback to their use in transplantation [48]. It is therefore viewed that the iPSC derived cells should be examined prior to their applications in clinical use and transplantations [49]. Practical application of this technology in clinics require to resolve these issues involving safe policy to genetically modify iPSCs and their differentiation into appropriate cell types in vitro, and removal of tainting stem cells before transplantation [50]. With adequate technological advancements and acceptance of human ethics, the iPSC technology will definitely be a boon to public health benefits.

\section{Box 1:}

\section{Stem Cell Technology in Saving the Endangered Species}

The iPSC technology has proved itself to be a boon for numerous problems related to our human health. Apart from this, this technology can also become answer for one of the most important problem of endangered species [46]. Although the role of natural selection in species extinction cannot be entirely ruled out, but many of these endangered species are threatened by notorious human activities. Since there are several indigenous species which are on the verge of extinction, and saving these endangered species from extinction is a concern. In this concern, a welcome move to save the endangered species has already taken, where cells from two endangered species are reprogrammed to form stem cells as found in early stage embryo [51]. Specifically, a northern white 
rhino and a drill monkey were the first of their kind to have their cells getting transformed into stem cells which can be stored and further multiplied in cultures [51]. These cells can form any kind of cells including genital cells which could be further used to increase their population. Sperm cells can be formed from those stem cells whenever required in future to inseminate females and increase in their population. To this respect, there are many indigenous species of flora and fauna in India which are not found elsewhere in the world, and many are endangered and many are on the verge of extinction. Application of iPSC technology will not only help in saving these precious species from extinction, but also help maintaining a stable population size, thereby save the species from extinction [52].

\section{Conclusion}

Induced Pluripotent Stem Cells (iPSCs) technology has completely changed the direction of clinical health care system. Taken together, the HESCs and iPSCs offer excellent technological advancement for therapeutic purposes, and make them promising future tools for developmental biology and in field of regenerative medicine. It therefore seems that more research on this technology will surely be of enormous help in public health. Its application in personalized-medicine has been started recently. Research work in this field can bring tremendous changes to the society. In this concern, the stem cell banking facilities have provided new avenues for preserving the cord blood of the new-borne child and treat them in future by using her/his own preserved stem cells. Although this process is not that easy to implement, yet it creates a ray of hope for solving numerous problems faced by us during our life time. However, like all new technologies, the output from stem cell research requires to be evaluated more closely. There are lots of ethical concerns related to it, which needs to be rectified as we move forward in its deep research. These ethical concerns cannot be ignored. Furthermore, with proper guidelines on ethical issues and extended research following these strategies, the stem cell technology is expected to not only be of huge benefit to human health, but also the benefit can be extended to the survival of endangered animals as well. The broad spectrum related to stem cell technology cannot be ignored especially the benefits of IPSC related techniques.

\section{Acknowledgements}

The authors thank Dr. T. Lahiri, Head of the Department of Applied Science, IIIT, Allahabad for encouragements.

\section{References}

[1] Carlson, B.M. (2007) Stem Cells, Plasticity, and Regeneration, Principles of Regenerative Biology. Acedemic Press, 239-258.

[2] King, R.S. and Newmark, P.A. (2012) Cell Biology of Regeneration. Journal of Cell Biology, 196, 553-562. http://dx.doi.org/10.1083/jcb.201105099

[3] Prabhakaran, M.P., Venugopal, J., Ghasemi-Mobarakeh, L., Kai, D., Jin, G. and Ram Krishna, S. (2012) Stem Cells and Nanostructures for Advanced Tissue Regeneration. Advanced Polymer Science, 246, 21-62. http://dx.doi.org/10.1007/12_2011_113

[4] Barrere, F., Van-Blitterswijk, C.A. and Groot, K.A. (2006) Bone Regeneration: Molecular and Cellular Interactions with Calcium Phosphate Ceramics. International Journal of Nanomedicine, 1, 317-332.

[5] Prasad, P., Desai, R., Bansal, S., Shirsat, P. and Raipure, P. (2015) Stem Cells_Emerging Concepts in Dentistry. Annals of Medicinal Chemistry and Research, 1, 1006.

[6] Dubie, T., Admassu, B., Sisay, T. and Shiferav, H. (2014) Basic Biology and Therapeutic Application of Stem Cells in Various Human and Animal Diseases. Journal of Cell Biology and Genetics, 4, 40-52.

[7] Singh, R.K., Gaikwad, S.M., Chatterjee, S. and Ray, P. (2014) Stem Cells: The Holy Grail of Regenerative Medicine. Engineering in Translational Medicine, 4471-4472. http://dx.doi.org/10.1007/978-1-4471-4372-7_2

[8] Mitalipov, S. and Wolf, D. (2009) Totipotencty Pluripotency and Nuclear Reprogramming. Advances in Biochemical Engineering/Biotechnology, 114, 185-199.

[9] Lin, H.T., Makotootsu, O. and Nakauchi, H. (2011) Stem Cell Therapy: An Exercise in Patience and Prudence. Philosophical Transitions B, 0334.

[10] Ning, L., Goossens, E., Geens, M., Saen, D.V. and Tournaye, H. (2012) Spermatogonial Stem Cells as a Source for Regenerative Medicine. Science Direct Middle East Fertility Society Journal, 17, 1-7. 
http://dx.doi.org/10.1016/j.mefs.2011.06.002

[11] Zhang, X., Stojkovic, P., Przyborski, S., Cooke, M., Armstrong, L., Lako, M., et al. (2006) Derivation of Human Embryonic Stem Cells from Developing and Arrested Embroys. Stem Cell, 24, 2669-2676. http://dx.doi.org/10.1634/stemcells.2006-0377

[12] Stadtfeld, M. and Hochedlinger, K. (2010) Induced Pluripotency: History, Mechanism, and Applications. Genes and Development, 24, 2239-2263. http://dx.doi.org/10.1101/gad.1963910

[13] Patel, M. and Yang, S. (2010) Advances in Reprogramming Somatic Cells to Induced Pluripotent Stem Cells. Stem Cell Review, 6, 367-380. http://dx.doi.org/10.1007/s12015-010-9123-8

[14] Tada, M., Tada, T., Lefebvre, L., Barton, S.C. and Azim, S.M. (1997) Embryonic Germ Cells Induce Epigenetic Reprogramming of Somatic Nucleus in Hybrid Cells. EMBO Journal, 16, 6510-6520. http://dx.doi.org/10.1093/emboj/16.21.6510

[15] Cyranoski, D. (2014) The Black Box of Reprogramming. Nature, 516, 162-164. http://dx.doi.org/10.1038/516162a

[16] Tsai, C.C. and Hung, S.C. (2012) Functional Roles of Pluripotency Transcription Factors in Mesenchymal Stem Cells. Cell Cycle, 11, 3711-3712. http://dx.doi.org/10.4161/cc.22048

[17] Kim, J.S., Choi, H.W., Choi, S. and Do, J.T. (2011) Reprogrammed Pluripotent Stem Cells from Somatic Cells. International Journal of Stem Cells, 4, 1-8. http://dx.doi.org/10.15283/ijsc.2011.4.1.1

[18] Ramsden, C.M., Powner, M.B., Carr, A.J.F., Smart, M.J.K., Cruz, L. and Coffey, P.J. (2013) Stem Cells in Retinal Regeneration: Past, Present and Future. Development, 140, 2576-2585. http://dx.doi.org/10.1242/dev.092270

[19] Velasco, I., Salazar, P., Giorgetti, A., Ramos-Mejía, V., Castaño, J., Romero-Moya, D., et al. (2014) Concise Review: Generation of Neurons from Somatic Cells of Healthy Individuals and Neurological Patients through Induced Pluripotency or Direct Conversion. Stem Cells, 32, 2811-2817. http://dx.doi.org/10.1002/stem.1782

[20] Robinton, D.A. and Daley, G.Q. (2012) The Promise of Induced Pluripotent Stem Cells in Research and Therapy. Nature, 481, 295-305. http://dx.doi.org/10.1038/nature10761

[21] Yamanaka, S. (2012) Induced Pluripotent Stem Cells: Past, Present, and Future. Cell Stem Cell, 10, 678-684. http://dx.doi.org/10.1016/j.stem.2012.05.005

[22] Patel, M. and Yang, S. (2010) Advances in Reprogramming Somatic Cells to Induced Pluripotent Stem Cells. Stem Cell Review, 6, 367-380. http://dx.doi.org/10.1007/s12015-010-9123-8

[23] Plath, K. and Lowry, W.E. (2011) Progress in Understanding Reprogramming to the Induced Pluripotent State. Nature Reviews Genetics, 12, 253-265. http://dx.doi.org/10.1038/nrg2955

[24] Perán, M., María, A., García, M.A., López-Ruiz, E., Bustamante, M., Jiménez, G., et al. (2012) Functionalized Nanostructures with Application in Regenerative Medicine. International Journal of Molecular Science, 13, 3847-3886. http://dx.doi.org/10.3390/ijms13033847

[25] Okita, K. and Yamanaka, S. (2011) Induced Pluripotent Stem Cells: Opportunities and Challenges. Philosophical Transactions of the Royal Society B: Biological Sciences, 366, 2183-2197. http://dx.doi.org/10.1016/b978-0-12-381422-7.10013-6

[26] Ban, H., Nishishita, N., Fusaki, N., Tabata, T., Saeki, K., Shikamura, M., et al. (2011) Efficient Generation of Transgene-Free Human Induced Pluripotent Stem Cells (iPSCs) by Temperature-Sensitive Sendai Virus Vectors. Proceedings of the National Academy of Sciences of the United States of America, 108, 14234-14239. http://dx.doi.org/10.1073/pnas.1103509108

[27] Somers, J., Jean, J.C., Sommer, C.A., Omari, A., Ford, C.C., Mills, J.A., et al. (2010) Generation of Transgene-Free Lung Disease-Specific Human iPS Cells Using a Single Excisable Lentiviral Stem Cell Cassette. Stem Cell, 28, 17281740. http://dx.doi.org/10.1002/stem.495

[28] Yeo, J.C. and Ng, H.H. (2013) The Transcriptional Regulation of Pluripotency. Cell Research, 23, $20-32$. http://dx.doi.org/10.1038/cr.2012.172

[29] Huang, G.T.J. (2010) Induced Pluripotent Stem Cells-A New Foundation in Medicine. Journal of Experimental and Clinical Medicine, 2, 202-217. http://dx.doi.org/10.1016/S1878-3317(10)60033-2

[30] Phillips, M.J., Perez, E.T., Martin, J.M., Reshel, S.T., Wallace, K.A., Capowski, E.E., et al. (2014) Modeling Human Retinal Development with Patient-Specific Induced Pluripotent Stem Cells Reveals Multiple Roles for Visual System Homeobox 2. Stem Cells, 32, 1480-1492. http://dx.doi.org/10.1002/stem.1667

[31] Wu, S.M. and Hochedlinger, K. (2011) Harnessing the Potential of Induced Pluripotent Stem Cells for Regenerative Medicine. Nature Cell Biology, 13, 497-505. http://dx.doi.org/10.1038/ncb0511-497

[32] Khan, N., Pande, V. and Das, A. (2013) NAT2 Sequence Polymorphisms and Acetylation Profiles in Indians. Pharmacogenomics, 14, 289-303. http://dx.doi.org/10.2217/pgs.13.2

[33] Kalow, W. (2006) Pharmacogenetics and Pharmacogenomics: Origin, Status, and the Hope for Personalized Medicine. 
The Pharmacogenomics Journal, 6, 162-165. http://dx.doi.org/10.1038/sj.tpj.6500361

[34] Li, Y., Wu, W.H., Hsu, C.W., Nguyen, H.V., Tsai, Y.T. and Chan, L. (2014) Gene Therapy in Patient-Specific Stem Cell Lines and a Preclinical Model of Retinitis Pigmentosa with Membrane Frizzled-Related Protein Defects. Molecular Therapy, 22, 1688-1697. http://dx.doi.org/10.1038/mt.2014.100

[35] Chun, Y.S., Byun, K. and Lee, B. (2011) Induced Pluripotent Stem Cells and Personalized Medicine: Current Progress and Future Perspective. Anatomy \& Cell Biology, 44, 245-255. http://dx.doi.org/10.5115/acb.2011.44.4.245

[36] Abdullah, A.I., Pollock, A. and Sun, T. (2012) The Path from Skin to Brain: Generation of Functional Neurons from Fibroblasts. Molecular Neurobiology, 45, 586-595. http://dx.doi.org/10.1007/s12035-012-8277-6

[37] Medvedev, S.P., Shevchenko, A.I. and Zakian, S.M. (2010) Induced Pluripotent Stem Cells: Problems and Advantages When Applying Them in Regenerative Medicine. Acta Naturae, 2, 18-28.

[38] Teye, K., Tsuneoka, M., Arima, N., Koda, Y., Nakamura, Y., Ueta, Y., et al. (2004) Increased Expression of a Myc target Gene Mina53 in Human Colon Cancer. American Journal of Pathology, 164, 205-216. http://dx.doi.org/10.1016/S0002-9440(10)63111-2

[39] Zhang, M., Yang, C., Huixian, L.H. and Sun, Y. (2013) Induced Pluripotent Stem Cells Are Sensitive to DNA Damage. Genomics, Proteomics Bioinformatics, 11, 320-326. http://dx.doi.org/10.1016/j.gpb.2013.09.006

[40] Diekman, B.O., Christoforou, N., Willard, V.P., Sun, H., Sanchez-Adams, J., Leong K.W., et al. (2012) Cartilage Tissue Engineering Using Differentiated and Purified Induced Pluripotent Stem Cells. Proceedings of the National Academy of Sciences of the United States of America, 109, 19172-19177. http://dx.doi.org/10.1073/pnas.1210422109

[41] Logeart-Avramoglou, D., Anagnostou, F., Bizios, R. and Petite, H. (2005) Engineering Bone: Challenges and Obstacles. Journal of Cellular and Molecular Medicine, 9, 72-84. http://dx.doi.org/10.1111/j.1582-4934.2005.tb00338.X

[42] Schuster, J.A., Stupnikov, M.R., Ma, G., Liao, W., Lai, R., Ma, Y., et al. (2012) Expansion of Hematopoietic Stem Cells for Transplantation: Current Perspectives. Experimental Hematology and Oncology, 1, 12. http://dx.doi.org/10.1186/2162-3619-1-12

[43] Blenkinsop, T.A., Corneo, B., Temple, S. and Stern, J.H. (2012) Ophthalmologic Stem Cell Transplantation Therapies. Regenerative Medicine, 7, 32-39. http://dx.doi.org/10.2217/rme.12.77

[44] Koch, P., Kokaia, Z., Lindvall, O. and Brüstle, O. (2009) Emerging Concepts in Neural Stem Cell Research: Autologous Repair and Cell-Based Disease Modelling. Lancet Neurology, 8, 819-829. http://dx.doi.org/10.1016/S1474-4422(09)70202-9

[45] Gluckman, E., Ruggeri, A., Rocha, V., Baudoux, E., Boo, M., Kurtzberg, J., et al. (2011) Family-Directed Umbilical Cord Blood Banking. Haematologica, 96, 1700-1707. http://dx.doi.org/10.3324/haematol.2011.047050

[46] Geraghty, R.J., Capes-Davis, A., Davis, J.M., Downward, J., Freshney, R.I., Knezevic, I., et al. (2014) Guidelines for the Use of Cell Lines in Biomedical Research. British Journal of Cancer, 111, 1021-1046. http://dx.doi.org/10.1038/bjc.2014.166

[47] Barrilleaux, B. and Knoepfler, P.S. (2011) Inducing iPSCs to Escape the Dish. Stem Cell, 9, 103-111. http://dx.doi.org/10.1016/j.stem.2011.07.006

[48] Platt, J.L. (2010) Antibodies in Transplantation. Discovery Medicine, 10, 125-133.

[49] Nakano-Okuno, M., Borah, B.R. and Ichiro, N.I. (2014) Ethics of iPSC-Based Clinical Research for Age-Related Macular Degeneration: Patient-Centered Risk-Benefit Analysis. Stem Cell Reviews, 10, 743-752. http://dx.doi.org/10.1007/s12015-014-9536-X

[50] Yee, J. (2010) Turning Somatic Cells into Pluripotent Stem Cells. Nature Education, 3, 25.

[51] Ben-Nun, I.F., Montague, S.C., Houck, M.L., Tran, H.T., Garitaonandia, I., Leonardo, T.R., et al. (2011) Induced Pluripotent Stem Cells from Highly Endangered Species. Nature Methods, 8, 829-831. http://dx.doi.org/10.1038/nmeth.1706

[52] Callaway, E. (2011) Could Stem Cells Rescue an Endangered Species? Nature, Published Online. 


\section{Abbreviations}

HESCs, Human Embryonic Stem Cells iPSCs, Induced Pluripotent Stem Cells ESCs, Embryonic Stem cells SCNT, Somatic Cell Nuclear Transfer HPCs, Hematopoietic Progenitor Cells ICM, Inner Cellular Mass 